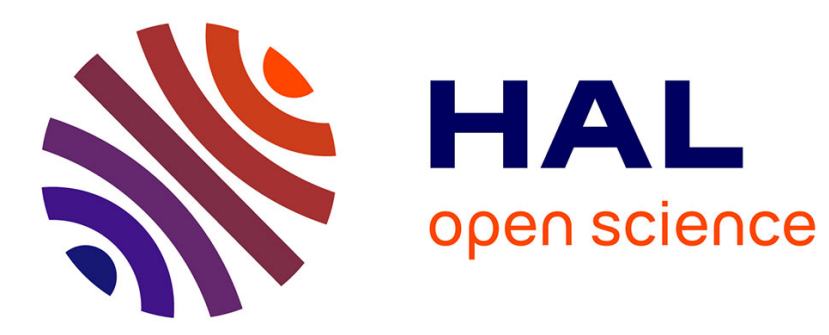

\title{
Manufacturing Enterprise Control and Management System Engineering: Paradigms and Open Issues
}

Gérard Morel, Hervé Panetto, Marek Zaremba, Frédérique Mayer

\section{To cite this version:}

Gérard Morel, Hervé Panetto, Marek Zaremba, Frédérique Mayer. Manufacturing Enterprise Control and Management System Engineering: Paradigms and Open Issues. IFAC Annual Reviews in Control, 2003, 27 (2), pp.199-209. 10.1016/j.arcontrol.2003.09.003 . hal-00121506

\section{HAL Id: hal-00121506 https://hal.science/hal-00121506}

Submitted on 27 Feb 2011

HAL is a multi-disciplinary open access archive for the deposit and dissemination of scientific research documents, whether they are published or not. The documents may come from teaching and research institutions in France or abroad, or from public or private research centers.
L'archive ouverte pluridisciplinaire HAL, est destinée au dépôt et à la diffusion de documents scientifiques de niveau recherche, publiés ou non, émanant des établissements d'enseignement et de recherche français ou étrangers, des laboratoires publics ou privés. 
MOREL G., PANETTO H., ZAREMBA M.B., MAYER F. (2003). Manufacturing Enterprise Control and Management System Engineering: paradigms and open issues. IFAC Annual Reviews in Control. 27/2, 199-209, Elsevier, December 2003

\title{
MANUFACTURING ENTERPRISE CONTROL AND MANAGEMENT SYSTEM ENGINEERING: PARADIGMS AND OPEN ISSUES
}

\author{
Gérard Morel $^{\mathrm{a}}$, Hervé Panetto ${ }^{\mathrm{a}}$, Marek Zaremba ${ }^{\mathrm{b}}$, Frédérique Mayer ${ }^{\mathrm{c}}$ \\ ${ }^{\mathrm{a}}$ CRAN CNRS/UHP, University Henri Poincaré Nancy I, F 54506 Vandoeuvre-les-Nancy, France \\ E-mail: \{Herve.Panetto, Gerard.Morel\}@cran.uhp-nancy.fr\} \\ bépartement d'informatique et d'ingénierie, Université du Québec, Gatineau, Québec J8X 3X7, Canada \\ E-mail: zaremba@uqo.ca \\ ${ }^{\mathrm{C}}$ ERPI INPL, 8, rue Bastien Lepage, BP 647 - F 54010 Nancy Cedex, France \\ E-mail: Frederique.Mayer@ensgsi.inpl-nancy.fr
}

\begin{abstract}
Over several decades, control theory has developed its own set of more or less formal modelling techniques designed to automatically control the dynamic behaviour of complicated manufacturing systems and processes. The emerging Internet society is addressing new enterprise control and management integration (ECMI) challenges for agile business to manufacturing (B2M) purposes which enlarge the traditional setting of Automation Engineering to the systems engineering (SE) approach. In order to cope with the increasing complexity of integrating intelligence/information-intensive manufacturing automation within the networked manufacturing enterprise, Automation Engineering should be integrated into the systems engineering approach to achieve a holistic approach that treats in fine the technical operational manufacturing system emerging from the deployment of an ad hoc combination of formal and informal partial models. This paper emphasises that a Holonic Manufacturing Execution System Engineering (HMESE) approach should be a relevant B2M SE approach along with other relevant scientific, industrial and educational areas dealing with information and intelligence control and management issues in agile automation. Copyright (C) 2003 IFAC
\end{abstract}

Keywords: Automation Engineering, Systems Engineering, Intelligent Manufacturing Systems, Enterprise Integration and Networking, Manufacturing Plant Control, Large Scale Complex Systems, Education

\section{INTRODUCTION}

Manufacturing automation has faced significant challenges over the twenty past years to meet the changing goals of the manufacturing enterprise in the context of the next generation of manufacturing systems. Those challenges, defined in the broad framework of the industry-led international IMS $^{1}$ initiative, were discussed by (Yoshikawa, 1995).

\footnotetext{
${ }^{1}$ Intelligent Manufacturing Systems international initiative; http://www.ims.org

Profs. M.B. Zaremba and G. Morel and Associate Profs. H. Panetto and F. Mayer are respectively: member of the IFAC Technical Board, Chairman of the IFAC TC5.1 "Manufacturing Plant Control", Vice-Chairman of the IFAC TC5.3 "Enterprise Integration and Networking" and Vice-Chairwoman of the IFAC TC9.2 “Social Impact of Automation”.
} 
A form of technical intelligence that goes beyond simple information and is embedded into manufacturing systems components and within the products themselves is playing a prominent role as the pivotal technology that makes it possible to address agile B2M issues (Fig. 1) (Filos and Banhan, 2001)

(Insert Fig. 1 here)

A host of enterprise systems (Fig. 2) ranging from MEMS (Micro Mechatronics Systems), MES (Manufacturing Execution Systems) and IMS (Intelligent Manufacturing Systems) to ERP (Enterprise Resource Planning), APS (Advanced Planning Systems) and CRM (Customer Relationship Management) (Ollero, et al., 2003) aim to facilitate integration of the manufacturing chain within the networked enterprise, in order to control and to manage the customized manufacturing of both goods and services as desired by the Internet society.

(Insert Fig. 2 here)

Nevertheless, the ability of such information- and communication-intensive automation technologies to execute agile manufacturing is highly dependent on the quality of the SE process (Fig. 3) which is concurrently shared by different engineering areas, mainly process engineering, electrical engineering, automation engineering and information engineering for enterprise-control integration issues.

(Insert Fig. 3 here)

This concern has been previously addressed in software engineering in the early 1980s (Humphrey, 1998) and led to the concept of process maturity descriptive framework (Paulk, et al., 1995) applied in various areas in order to improve their continuous best practices (Hollocks in Kosanke and Nell, 1997; Curtis, et al., 2001).

Throughout sections 2, 3, 4 and 5, this paper demonstrates, along with relevant scientific, industrial and educational areas dealing with information and intelligence control and management issues in manufacturing, that System is an artefact too often associated with a high degree of reductionism and a lack of sound foundation in General System Theory (Simon, 1990) for meeting B2M-integration understanding and modelling. The key issue is always to design complex emergent systems so as to provide a model of a real system through a prescriptive approach based on a common understanding of the modelled object, and not merely through a descriptive one applying a given framework or technique to partially model a system. (Wortmann in Kosanke and Nell, 1997).

Section 6 argues that the specialisation of a Unified Modelling Language (UML) for enterprise (UEML) and manufacturing (UMML) integration issues should facilitate the multi-models interoperability of the different automation-oriented qualitative and quantitative modelling techniques involved in a practical ECMI process.

Section 7 stresses that a Holonic Manufacturing Execution System Engineering (HMESE) approach should be a relevant B2M SE approach that integrates, through specialised UEML and UMML, the agile system features of the Holonic Manufacturing System (HMS) paradigm with the MES features of the IEC/ISO 62264 (ISO, 2002; Brandl, 2001) and the distributed automation features of the IEC 61499 (IEC, 1998; Christensen, 2003).

This paper finally underlines the merits and the perspectives of establishing such an ECMI SE framework facilitating the definition, development and deployment of agile automation.

\section{MANUFACTURING ENTERPRISE SYSTEM ENGINEERING PARADIGMS}

Integration in Manufacturing (IiM) is the first systemic paradigm to organize humans and machines as a whole system (Vernadat, 1996), not only at the field level, but also at the management and corporate level to produce an integrated enterprise system. IiM is a mature information technology-oriented approach. Business process software and MES are now available to meet the requirements of this fully computerized and automated integration previously addressed by Computer Integrated Manufacturing or Process systems (CIM/CIP). The goal is to digitally integrate the entire manufacturing chain, from design through manufacturing, through supply management, to maintenance and service, over the whole product life cycle, from the concept of a product to its final end use and disposal. Major problems remain with respect to the interface between the enterprise corporate level and the manufacturing shop floor level, so that management and operation decisions within a closed loop are facilitated to pace the production according to the life-cycle dynamics of the products, processes and humans inside and outside the enterprise. Several modelling frameworks are currently being proposed to integrate production planning and control with process automation by harnessing he increasing capabilities of Information Technologies around a common information system (data communication, storage and processing) and CAD/CAE/CAM/PPDM technologies (Computer Aided Design / Computer Aided Engineering / Computer Aided Manufacturing / Product Process Data Management). Despite many efforts to achieve international 
consensus (papers in Kosanke, et al., 1997; 2003) with regard to enterprise organisational ontology, unification in a scientific corpus of the set of concepts, theories, models, methods, methodologies, languages and tools for enterprise modelling remains pending in order to completely describe the information aspects of an integrated manufacturing system (papers in Kopacek, et al., 2001).

Intelligence in Manufacturing Systems (IMS) is another promising systemic paradigm (Valckenaers, 1998; 2000) for organising humans and machines into a networked system evolving into a unitary extended/virtual enterprise for all its practical world-wide manufacturing purposes (papers in Morel and Grabot, 2003). The next generation of manufacturing systems will have to distribute the digital intelligence across the field factory in order to enable flexible and autonomous operation of distributed units to transform information flows into product flows. Although intelligence for manufacturing has been conceptually addressed in many ways from the 1980's towards Yoshikawa's vision, including theoretical foundations for intelligent control (Zaremba and Morel in Banaszak, 2003), two technologies have recently generated a considerable amount of attention: Multi-Agents Systems (MAS) and HMS (Marik and Pechoucek, 2001). Whereas MAS have their origin in the Distributed Artificial Intelligence community as software technology, HMS comes directly from the IMS community as a manufacturing technology (Valckenaers, 2001). Both have shown promising results and appear as key information/communication technological approaches to meet the dynamic requirements of agile manufacturing/fractal factory (papers in Monostori, et al., 2003). According to the generally accepted fact that intelligence always manifests itself in behaviour, the IMS paradigm breaks with the well-established Cartesian approach, and advances a new behaviour-based modelling strategy stating that the system behaviour emerges through the dynamics of the interactions of basic manufacturing agents within the manufacturing environment (Valckenaers in Morel and Grabot, 2003). In this perspective, IMS is neither a mature information technologyoriented approach nor a system automation one.

Faced with the lack of a complete modelling framework for industry, Systems Engineering ${ }^{2}$ currently remains the most pragmatic alternative which can make it possible to put the above two more or less holistic approaches into practice.

This new awareness is challenging the scientific, industrial and education communities to consider how to control and to manage the increasing information-interaction-intelligence complexity that should be deployed for agile automation and ECMI.

Consequently, the main paradigm shift in manufacturing automation is to bridge the gap between the traditional hierarchical behaviour-predetermined modelling approach towards more appropriate heterarchical behaviouremerging modelling approaches, so that the system can be automatically controlled according to system theory and informationally/intelligently structured according to SE rules.

\section{SYSTEM THEORY, AUTOMATIC CONTROL AND AUTOMATION ENGINEERING}

As formally addressed by Fusakoa, et al. (1983), the process of automating a system consists in satisfying the following conditions: Dynamics $\wedge$ Control Rules $\supset$ Goal. In the context of manufacturing, this process is currently performed in order to define the unknown control rules (in the form of discrete-event behaviour) of the known dynamics of physical processes (in the form of discrete-time behaviour) for the purpose of optimising given performance objectives globally assigned to the system (in the form of information-based behaviour). This formulation is compliant with System Theory (Cassandras, et al., 1999) which remains the scientific foundation for Automatic Control of the dynamic behaviour of manufacturing systems. Those systems are considered as complicated artefacts consisting of technologically interconnected simpler and more complex components that dynamically interact with their environment. This approach opens the control system field to the development of powerful intelligent control techniques which incorporate adaptation, learning, self diagnosis and reconfiguration/repair (Monostori in Kopacek, et al., 2001), and intelligent controllers which integrate capabilities of novel hardware and software technologies. The hybrid nature of real manufacturing systems compels this discipline to address theoretically challenging issues of the integration of event-driven and timedriven components in order to better take into account the system scalability. The common thread in recent advances in this area is the willingness to broaden the control mindset beyond the boundaries of classical control-theoretic approaches by bringing it closer to Computer Science techniques in order to meet distributed networked automation embedding more en more software and Information Communication Technologies (ICT). However, the main concern in achieving agile automation is that the notion of System has been so closely associated with hierarchical models (Fig. 3, level 2) that to regard information ordering as a dynamic and emergent characteristic of self-organising complex systems is to challenge the current way of thinking that order

\footnotetext{
${ }^{2}$ INternational COuncil on Systems Engineering, http://www.incose.org
} 
can only occur through centralized control imposed through a prescriptive system control design, whether or not based on intelligent techniques.

Although the sound mathematical foundations of this discipline make it possible to handle the controlinformation complexity of random, stochastic, non-linear and chaotic processes, these formal techniques are not efficient enough to support the process of automating the manufacturing of industrial products by integrating all the aspects of the manufacturing chain over the whole product/process life cycle and across the entire information enterprise (quality, maintenance, technical management, process planning, and so on, including engineering). The systemic feature of Automation Engineering remains the same: to extend the dynamical vision of system control, so that it takes into account the functional $(\supset)$ and organisational/operational $(\wedge)$ manufacturing systems requirements as well as their behavioural ones (Camarinha-Matos, et al., 2000).

Apart from the intrinsic performance of the controlled system, automation engineering refers mainly to Cybernetics (Lhote, at al., 1999) in terms of controlling the set of manufacturing finalities which deal with the transformation of physical/energy flows and event-driven/data-driven information flows into goods and services as well as with their interfacing through interoperable (Thomesse, 1998; Starosviecki, et al., 1996; Iung, et al., 2001) mechatronic actuation and measurement systems. The increasing impact of ICT upon e-manufacturing automation raises various and new interface B2M challenges within these even more flexible and less hierarchical enterprise architectures. System is largely associated with large-scale complicated manufacturing system engineering using ICT in order to facilitate the integration and the interoperability (Fig. 3, levels 3 \& 4) of manufacturing systems to achieve a global Enterprise System. Despite important IEC 61499 and IEC/ISO 62264 ongoing standardisation efforts towards distributed automation and B2M interfacing as well as system workflow (Kim and Nof, 2002), the field of agile automation engineering requires a substantial effort to develop formal techniques to deal with the complexity in moving from the hierarchical IiM to the heterarchical IMS paradigm for practical issues.

\section{SYSTEMS ENGINEERING AND SYSTEMICS}

As stated above, information - based nowadays on e-information technology - has become the central means of integrating manufacturing automation as a coherent whole, of distributing it as autonomous units, of communication between units, and of computationally controlling manufacturing agents in order to meet enterprise dynamic organisational/operational $(\wedge)$ goals $(\supset)$. The cooperative role played by human and technological agents in agile manufacturing automation in reaching a collective goal raises a question of fundamental importance concerning the complexity of controlling and managing the multiple information artefacts that circulate up and down the levels of manufacturing organizations through individual agents.

Systems Engineering is first of all a practicable management technology for coping with this increasing information-based technical and knowledge complexity in order to bring the system into operational service. Normative SE capability models (Fig. 4) developed by professional associations provide best-practice guidelines in order to ensure system definition, system development and system deployment taking into account the multidisciplinary aspects of engineering systems.

\section{(Insert Fig. 4 here)}

Among many key elements in making the best possible decision in a Systems engineering project, formal approaches using theorem-proving constructs and set-theory notation (Shell, 2001) combined with unified modelling techniques (papers in Kopacek, et al., 2001) appear well suited in an early phase of a project life-cycle for checking global coherence and partial consistency between all the various requirements and specifications of different functions of the system. These set-theory based prescriptive approaches (Feliot, 1997; Penalva, 1997) focusing on the system and on proper and comprehensive understanding of its objectives are the critical link in bridging the gap with the normative descriptive approaches that focus primarily on the project and the qualitative and quantitative management of the engineer's activities.

Beyond reductionism, these system approaches also permit the practical application of Systemics as a rigorous General System Theory strategy for explaining, understanding and predicting the complex properties that emerge from the interactions of numerous agents. Those interactions - even if relatively simple as it is the case with technological interactions - are not exhibited by individual agents, and allow the system to self-organise for the purposes of holistic design and operation. Conversely the emerging organisation constrains and modifies agent's behaviour, through the processes of cooperation, competition and negotiation. 
Ordering information in modern information-intensive engineering organisations and inferring the behavioural rules and mechanisms of parts from the emergent behaviour of a whole system raises new Systemics, Cognitics (Dessimoz, 2002) and Kenetics (Ferber, 1994) concerns, which are challenging the current top-down and bottom-up system modelling approaches (Fig. 5) in favour of a more interdisciplinary way of thinking by research, industry and educational organisations, and by individuals (Boland, et al., 2001).

\section{(Insert Fig. 5 here)}

System is more closely associated with Systemics in Systems Engineering, where current Enterprise Systems systemise the use of human and technical resources to determine what an Enterprise should do, how an Enterprise could do it, and so on (Weston, 1999). Notwithstanding the fact that professional and technical associations have proposed standardised frameworks defining the processes (acquisition and supply, technical management, system design, product realisation, technical evaluation) for engineering a system, more fundamental work should be done to formalise (to capture, to model and to verify) user requirements, engineers' knowledge, system operation, etc., to make system design more an engineering process than an art.

\section{EDUCATION AND TRAINING EXPERIMENTS}

A recent scientific study addresses the difficulties high-level university students experience when learning about complex systems phenomena (Jacobson, 2001). Others industry-driven works addressed the need for agile workforce in competitive organizations (Curtis, et al., 2001) to improve and to adapt continuously their best practices in response to the socio-technical changes.

Consequently, as any engineer is first a student or a trainee, there is a critical educational and training need to help these learners to accept and to understand systems engineering (Asbjornsen and Hamann, 2000) and its conceptual foundations involving knowledge about complexity and Systemics in general (Mayer, 1995).

Our pedagogical experiment in a CIME networked centre ${ }^{3}$ puts into practice some sound systemic precepts in order to help students to grasp the conceptual framework of the ECMI paradigm addressed in our metrics (Fig. 3) before having to practice the relevant engineering techniques and automation information technologies currently involved in IiM and IMS.

One main objective is to break away from isolated teaching/learning and a Cartesian approach (Fig. 3, levels 1 \& 2) (Fig. 5, top-down approach) and move towards collaborative teaching/learning and a systemic approach (Fig. 3, levels 3 \& 4 \& 5) (Fig. 5, bottom-up approach).

Recognising that any system is more than the sum of its parts and emerges from the interactions between its parts as a logically-ordered molecule composed of multi-models and multi-points of view as the result of an atomic interaction between the manufacturing environment and the product to be manufactured (Fig. 6), we assumed in Mayer, et al., (1996) that the different engineering areas involved in IiM and IMS have to be taught and learnt according to the logical rules needed for formally building a system.

\section{(Insert Fig. 6 here)}

A first approach consists in defining, both for trainers and trainees, the backbone of an integrated distributed CMMS/IAMS (Control Management and Maintenance System/Intelligent Actuation and Measurement System) (Iung, et al., 2001) as a common reference model for understanding the basic behaviour of one manufacturing system in a particular operational situation of workshop control and management integration. The idea is to focus the different courses and engineering tutorials of different teachers on a unique target-system in order to better share the necessary and sufficient knowledge and skills required for plausible system behaviour. Each student has to restate his individual knowledge and skill and the related practical works in the form of a hypertext tutorial which describes in a first dimension the system architecture engineering issues and, in a second dimension, the particular sub-systems engineering issues. According to the Fig. 6 precept, this approach appears really efficient to carry out the level 3 of our metrics by facilitating the ordering of cooperative teaching with a system-driven planning rather than with only a time-driven one. This approach is also well accepted by students for transforming isolated knowledge's into structured skills by opening their mind over Cartesian reasoning. However, the major barrier to deploy this qualitative approach is not in the foundation of the approach itself, but in its instrumentation in order to meet more quantitative aspects for pedagogical purposes. Some of these training principles have been formalised to market an industrial software tool for Computer-Aided distance-training

\footnotetext{
${ }^{3}$ www.aip-primeca.net
} 
design (Panetto in Robert, 2001). This tool should help, not only in the design and assembly of shared multimedia course materials, but also - and it is a key point - in the formalisation of learning paths (Table 1) which facilitate individualised learning-by-skills processes always starting from a working and practical problem situation to be solved.

(Insert Table 1 here)

Up to now, the level 4 of our metrics is carried out by workflow modelling based on the NIAM/ORM method (Halpin, 1998) in order to facilitate the emergence of natural-binary-language based knowledge-constructs of the modelled common learning situation, which can be then translated into UML for information system engineering purposes.

In order to carry out the level 5 of our metrics, we have recently found this approach can be made highly efficient for cooperative teaching and individual learning by using an XP-like approach currently applied in agile software development (Williams and Kessler, 2002). The objective is to emphasis the students' collective skills in a systems engineering organisation by sharing a framework of core concepts on agility in manufacturing, Systemics principles and generalisation in modelling process. As an example, one objective could be to minimise the modelling distance between the different discrete-event driven behavioural models of a productdriven control (MacFarlane, in Morel and Grabot, 2003) developed for specification, design, simulation, coding, etc., purposes with different engineering tools. During this XP-like phase of the learning process, many unresolved issues are refined by the students on a same conceptual basis in order to facilitate the emergence of a plausible operational system. Each individual has to achieve his particular hypertext scenario through the collective background gained. This approach appears promising because it is achieving the formal teachersdriven learning by a 'free-style' students-driven learning-by-doing which emphasises their ability to combine ad hoc formal and informal partial knowledge and skills as in any practical SE process. Computerizing this last pedagogical approach is still an open issue which should take benefit of future XP software environments, but raises, in our feeling, the problem of keeping essential the role of the human face-to-face teacher-learner and learner-learner interaction for carrying out complexity in SE.

Although an integrated framework is not yet defined, these systemic approaches ensure an evolutionary improvement path through the five levels of our metrics in order to cope with complexity in ECIM issues.

\section{TECHNOLOGIES FOR ENTERPRISE AND PROCESS MODELS INTEROPERABILITY}

New advances in Enterprise Engineering (EE) methods as well as a strong need to progress towards Enterprise Integration (EI) call for efficient enterprise modelling languages and advanced computer-based tools. Enterprise modelling is concerned with representation (Panetto in Kosanke, et al., 2003) and analysis methods for design engineering and automation of enterprise operations at various levels of detail (e.g., coarse modelling, reengineering, detailed design and analysis, performance evaluation, etc.). Various methods and modelling techniques have been proposed over the last decade to cover different aspects of enterprise modelling, e.g., ARIS, BONAPART, CimTool, FirstSTEP, IDEF methods, IEM, IBM's FlowMark, PrimeObject and PROPLAN, to name a few. Various efforts are underway by standardisation groups (Fig. 7) to propose prenorms (CEN ENV 40003 (CEN, 1995) and CEN ENV 12204 (CEN, 1990)) at the European level, or standards (CEN/ISO WD 19440, ISO DIS 14258, ISO CD 15704 and ODP Enterprise language) at the international level. Other efforts aim for an international consensus among users concerning enterprise engineering and integration based on modelling technology (papers in Kosanke, et al., 2003). An IFAC-IFIP Task Force has developed a Generalised Enterprise Reference Architecture and Methodology (GERAM, 1997) as a generalisation of the CIMOSA (Open System Architecture for CIM) (AMICE, 1993), GIM (GRAI Integrated Methodology) (Doumeingts, et al., 1998) and PERA (Williams, 1992) architectures which enlarges the horizon description to the concept of Virtual Enterprise or Extended Enterprise.

(Insert Fig. 7 here)

ISO and ISA are establishing a joint working group to develop ISA-95 (ISA, 2000) on Enterprise Control Systems Integration. The resulting standard IEC/ISO 62264 Enterprise Control Systems Integration is a multipart set of standards that defines models and establishes terminology for defining the interfaces between an enterprise's business systems and its manufacturing control systems. It describes in a rather detailed way the relevant functions in the enterprise and the control domain and the objects normally exchanged between these domains. It is becoming the accepted model for B2M integration (Brandl, 2001). 
In order to reach a broad consensus for model information exchange between enterprise modelling tools, the UEML (Unified Enterprise Modelling Language) project (UEML, 2003) has defined an initial set of generic constructs with the aim of achieving interoperability between them. In recent years, one of the most notable research efforts has been directed to improvement of interoperability (mainly software interoperability), a critical success factor for enterprises striving to become more flexible and to reduce the effort required to establish and sustain cooperation. Software interoperability has been especially addressed by specific software markets such as EAI and XML based solutions. However, these solutions mostly focus on compatibility of distinct formats without looking at the so-called modelling domain, i.e., the domain stating the rationale behind the software and providing reasons for building software. Information about the modelling domain, without taking into account any software issues, is essential to achieving greater interoperability. It is likely to be really difficult or even impossible to understand and recover this kind of information from software. As a consequence, this information should be associated with the software from the beginning and should be continuously maintained.

A UEML language should be a key component embedded in a complete environment and should cover information concerning the entire enterprise domain, by providing all the needed modelling capabilities allowing representation of the enterprise domain. As a consequence, some of the main objectives of this project are that the UEML should:

(i) Capitalise on the existing knowledge about enterprise modelling and

(ii) Make existing modelling tools more interoperable by enabling some kind of exchange between them.

It should be noted that these two points are complementary and both are needed.

The UEML could solve the issue of horizontal interoperability at the enterprise level. Thus, as information is controlled at the Automation level, it should need to be defined through a vertical interoperability approach from the product that produces it through the Manufacturing Execution System that consolidates it to the Enterprise Business Processes that use it. Standards such as the IEC/ISO 62264 together with the IEC 61499 function block draft standard for distributed industrial-process measurement and control systems could partially solve the vertical interoperability problem from the Business to the Manufacturing levels (Fig. 7).

Consequently, as a prelude to building such a vertical information system dealing with physical process constraints $^{4}$, we are currently working on the definition of a UMML (Unified Manufacturing Modelling Language) that should serve as a pivotal language ensuring a common understanding of the product information along its whole life cycle. Applying AUTO-ID technology (MacFarlane in Morel and Grabot, 2003), that information can be embedded in physical objects according to the HMS paradigm, in order to ensure the traceability of customized products, goods for manufacturing issues and services for logistics issues. Such a holonic approach requires to aggregate separated object views and constructs of the IEC/ISO 62264 standard in order to define the relevant holons.

\section{TOWARDS HOLONIC MANUFACTURING EXECUTION SYSTEM ENGINEERING}

Among the many reasons to combine HMS with standardised MES Automation technology to create an efficient System Engineering approach for Agile Manufacturing Enterprise Control Integration are:

- A general consensus exists in the IMS/HOLOMAS (Marik and Pechoucek, 2001; Norrie and Brennan, 2002) community that the HMS paradigm offers a better fit with Enterprise-control integration at the automation level than the MAS paradigm which has a better fit with Enterprise-management integration with the Business level;

- HMS is primarily a bottom-up systems engineering approach ensuring, by definition, consistency between the physical goods and their related information services for all product-driven control and management issues induced by the manufacturing customization (MacFarlane and Bussmann, 2003);

- Ordering of physical holons in accordance with process physical/energy laws is a core guideline in the emergence of the system model which helps to ensure ordering data-driven management and eventdriven control of information holons;

- UML has a pivotal role for ensuring Business/Process software applications interoperability by the mean of specialised UEML/UMML, as well as for unifying standards notation such as IEC/ISO 62264 and IEC 61499.

\footnotetext{
${ }^{4}$ FIPA, AUML, www.fipa.org
} 
Our ongoing work deals with the adaptation of an Information Systems Engineering tool ${ }^{5}$ into a HMSE tool (Fig. 11) for ECMI applications, mainly for product-driven control and management purposes. The HMS architecture is designed at the conceptual level by a Holonic Process Model (HPM) (Fig. 8), derived from a Business Process Modelling technique which first describes firstly the exchange of holons flows with regard to the manufacturing environment and then describes the refinement of these holons flows according to their transformation within the manufacturing system. These holons flows are characterised with four different systemic modalities (Leger and Morel, 2001) specifying the Having To Do (HTD), Knowing How To Do (KHTD), Being Able To Do (BATD), Wanting To Do (WTD) role of each holon, as product, resource, etc., according to its shape, space, time transformation throughout the manufacturing processes.

(Insert Fig. 8 here)

The content of the holons flows can be directly extracted in order to design the holon class diagram of a B2M application (Fig. 9).

(Insert Fig. 9 here)

Because of the special emphasis on the holons to be controlled, the meta-model of the tool has been modified in order to separate the holons properties which should be controlled from those attributes which should be only managed.

Fig. 10 shows an extract of the metamodel for a Holonic Process Model. Derived from the UML 2.0 metamodel (UML, 2003), this model formalises an Holon which as an information object, is defined by its attributes together with some properties that should be controlled for a particular application.

(Insert Fig. 10 here)

This conceptual HMS architecture should then be mapped in UML at the organisational and operational levels according to the IEC/ISO 62264 and IEC 61499 standards by separating the information holons - data-driven holons and event-driven holons - from the related physical ones. Further development aims to assist the synthesis of the holons automata and of the holons services in order to distribute them over the software technical architecture as intelligent products using AUTO-ID technology (MacFarlane, in Morel and Grabot, 2003).

\section{CONCLUSIONS}

Establishing a broader HMESE framework (Fig. 11) integrating standardised MES Automation technologies and unifying modelling languages should facilitate moving from the IiM to the IMS paradigm for ECMI issues. This pragmatic interpretation of the HMS paradigm should also contribute to bridging the gap between the enterpriseintegration community and the manufacturing-automation community in order to rationalise the current erratic ICT-based approaches. Our rationale on ECMI issues, outlined through this paper, led us to propose this HMESE framework which is our ongoing research and development roadmap that requires further substantial efforts for its efficient deployment in industry and education.

(Insert Fig. 11 here)

\section{REFERENCES}

AMICE (1993). CIMOSA - Open System Architecture for CIM, 2nd edition, Springer-Verlag, Berlin, ISBN 3540-56256-7, ISBN 0387-56256-7.

Asbjornsen D.A. and Hamann R.J. (2000). Towards a Unified Systems Engineering Education, IEEE Transactions on Systems, Man and Cybernetics, Part C: Applications and Reviews, 30, 175-182.

Banaszak, Z. and Zaremba, M. (Eds.) (2003). Special issue on Internet-Based Distributed Intelligent Manufacturing Systems. Journal of Intelligent Manufacturing. 14/1.

Boland D., Groumpos P., Jagdev H., Karcanias N., Bourrières J-P., Browne J., Krauth J., Morel G., Pels H., Sackett P., Thoben K-D. and Valckenaers P. (2001). Roadmap of the Network of Excellence in Intelligent Control and Integrated Manufacturing. European Community, ICIMS-NOE, n Esprit LTR 23447.

\footnotetext{
${ }^{5}$ MEGA International, www.mega.com
} 
Brandl D.L. (2001). Making the Business Case for Business to Manufacturing Integration, Proceedings of the International Congress of Automation, Systems and Instrumentation, Sao Paulo, Brazil, October.

Camarinha-Matos L.M., Afsarmanesh H. and Erbe H.H. (2000). Advances in Networked Enterprises : Virtual Organizations, Balanced Automation and Systems Integration; Book on the $4^{\text {th }}$ IEEE/IFIP BASYS Conference, Berlin, Germany, September 27-29, ISBN 0-7923-7958-6.

Cassandras, C.G. and Lafortune S. (1999). Introduction to Discrete Event Systems; Kluwer Academic Publisher, ISBN 0-7923-8609-4.

Christensen J.H. (2003). HMS/FB Architecture and its Implementation In: Deen S.M. (Ed.), Agent-Based Manufacturing: Advances in the Holonic Approach. Berlin/Heidelberg: Springer-Verlag, 53-87.

Curtis B., Hefley W.E. and Miller S.A. (2001). People Capability Maturity Model (P-CMM), Version 2, CMU/SEI-2001-MM-01, SEI, http://www.sei.cmu.edu, July.

Dessimoz J.D. (2002). Knowledge Management and Cognitics - Some Fundamental Aspects. Proceedings of the IPNet workshop, Saas-Fee, September 10-11.

Dias W.P.S., Subrahmanian E. and Monarch I.A. (2001). Ordering of Information in Engineering Design Organizations; Proceedings of the 10th INRIA Workshop on Modelling Cooperative Activities in Design. 217-233, Paris, June 27-28, ISBN 2-7261-1186-6.

Doumeingts G., Vallespir B. and Chen D. (1998). Decision modelling GRAI grid. Chapter in: P. Bernus, K. Mertins, G. Schmidt (Eds.). Handbook on architecture for Information Systems, Springer-Verlag.

Feliot C. (1997). Complex System Modelling: Integration and Formalisation of Models, PhD Thesis, LAILLille 1, (in French).

Ferber J. (1994). Kenetics : from MAS to Interactions Science. International Review of Systemics, 8, № 1, 1327, ISSN 0980-1472.

Filos E. and Banahan E. (2001). Towards the smart organization: an emerging organizational paradigm and the contribution of the European RTD programs. Journal of Intelligent Manufacturing, 12, 101-119.

Fusaoka A., Seki H. and Takahashi K. (1983). A description and reasoning of plant controllers in temporal logic; IJCAI.

Halpin T.A. (1998). Object-Role Modeling (ORM/NIAM). Handbook on Architectures of Information Systems.

Humphrey W. S. (1998). Characterizing the software process. IEEE Software, 5/2, 73-79.

Iung B., Neunreuther E. and Morel G. (2001). Engineering process of integrated-distributed shop floor architecture based on interoperable field components. International Journal of Computer Integrated Manufacturing, 14, No. 3, 246-262.

Jacobson M.J. (2001). Problem solving, cognition, and complex systems: differences between experts and novices. Complexity, 6, No. 3, 41-49.

Kim C. and Nof S.Y. (2002). CIM workflow. Guest editorial in Journal of Intelligent Manufacturing. 13/6.

Kopacek, P., Morel G. and Zaremba M.B. (Eds.) (2001). Information Control Problems in Manufacturing. Proceedings of the 10th IFAC INCOM'01 Symposium. Vienna, Austria, September 20-22.

Kosanke K. and Nell J. G. (Eds.) (1997). Enterprise Engineering and Integration, Proceedings of IFIP International Conference on Enterprise Integration and Modelling Technology, Esprit Project $n^{\circ} 21859,1$ ISBN 3-540-63402, Springer-Verlag, Berlin.

Kosanke K., Jochem R. Nell J.G., and Ortiz Bas A. (Eds.) (2003). Enterprise Inter-and intra organisational integration, Proceedings of IFIP International Conference on Enterprise Integration and Modeling Technology, ISBN 1-4020-7277-5, Kluwer academics.

Leger J.B. and Morel G. (2001). Integration of maintenance in the enterprise towards an enterprise modellingbased framework compliant with proactive maintenance strategy. Product Planning \& Control, 12/2, 176187.

Lhote F., Chazelet Ph. and Dulmet M., (1999). The extension of principles of cybernetics towards engineering and manufacturing. Annual Reviews in Control, 23, 139-148.

Marik, V and Pechoucek, M (Eds.) (2001). Special issue on industrial applications of Holonic and MultiAgent Systems. Journal of Applied System Sciences. 2/1.

Mayer F. (1995). Contribution to manufacturing engineering: application to pedagogical engineering within a CIME centre. PhD Thesis, CRAN-UHP, (in French).

Mayer F., Morel G. and Kapp K.H. (1996). Contribution to education engineering within a CIM centre. Proceedings of the research workshop of ERNET European project, World Scientific Publishing, September, Darmstadt, Germany.

McFarlane D. and Bussmann S. (2003). Holonic Manufacturing Control: Rationales, Developments And Open Issues, in Deen S.M. (Ed.), Agent-Based Manufacturing: Advances in the Holonic Approach. Berlin/Heidelberg, Springer-Verlag, 303-326.

Monostori, L., Kadar, B. and Morel, G. (Eds.) (2003). Intelligent Manufacturing Systems. Proceedings of the 7th IFAC IMS'03 Workshop. Budapest, Hungary, April 6-8. 
Morel G. and Grabot B (Eds.) (2003). Special issue on IMS. Engineering Applications of Artificial Intelligence, ISSN 0952-1976, Elsevier Science, 16/4.

Norrie D.H. and Brennan, R.W., (Eds.) (2002). Special issue on Holons: Autonomous and Cooperative Agents for Industry. Journal of Integrated Computer-Aided Engineering, 9/3.

Ollero A., Morel G., Bernus P., Nof S., Sasiadek J., Boverie S., Erbe H. and Goodall R. (2003). Milestone report of the Manufacturing and Instrumentation coordinating Committee: From MEMS to Enterprise Systems. IFAC Annual Reviews in Control, 26, 151-162, ISSN 1367-5788.

Paulk Mark C. (1995). How ISO9001 compares with CMM, IEEE Software, 74-83, January.

Penalva J.M. (1997). Complex systems modelling, PhD Thesis, CEA-Paris 11, (in French).

Robert M. (Ed.) (2001). Proceedings of EAEEIE Annual Conference on Innovations in Education for Electrical and Information Engineering, Nancy, May 15-17, 2001.

Shell T. (2001). Systems function implementation and behavioural modelling : system theoretic approach, International Journal of Systems Engineering, 4/1.

Simon H.A. (1990). Sciences of the Artificial. MIT Press

Starosviecki M. and Bayard M. (1996). Models and Languages for the Interoperability of Smart Instruments, Automatica, 32/6, 859-873.

Thomesse J.P. (1998). A review of the field-buses. Annual reviews in Control, 22, 35-45.

Valckenaers P. (Ed.) (1998). Special issue on Intelligent Manufacturing Systems. Computers in Industry, $37 / 3$.

Valckenaers P. (Ed.) (2000). Special issue on Intelligent Manufacturing Systems. Computers in Industry, 43/2.

Valckenaers, P (Ed.) (2001). Special issue on Holonic Manufacturing Systems. Computers in Industry, 46/3.

Vernadat F.B. (1996). Enterprise Modelling And Integration, principles and applications. Chapman \& Hall, London.

Weston R.H. (1999). Reconfigurable, Component-based systems and the role of Enterprise Engineering Concepts. Computers in Industry, 40, No. 2-3.

Williams, T.J. (1992). The Purdue Enterprise Reference Architecture, A Technical Guide for CIM Planning and Implementation, ISA, ISBN 1-55617-265-6.

Williams L.A. and Kessler R.R. (2002). Experimenting with industry's 'Pair-Programming' Model in the Computer Science Classroom, www. Agilealliance.org.

Yoshikawa H. (1995). Manufacturing and the $21^{\text {st }}$ Century - Intelligent Manufacturing Systems and the Renaissance of the Manufacturing Industry. Technological Forecasting and Social Change. 49, 195-213.

ISA (2000). ANSI/ISA 95.00-2000. Enterprise/Control System Integration - Part 1: Models and Terminology, Part 2: Object Model Attributes. The Instrumentation, Systems, and Automation society

CEN (1990), CEN/CENELEC ENV 40003. Computer-Integrated Manufacturing, Systems Architecture, Framework for Enterprise Modelling, Comité Européen de Normalisation, Brussels.

CEN (1995). CEN/CENELEC ENV 12204. Advanced Manufacturing Technology, Systems Architecture, Constructs for Enterprise Modelling, Comité Européen de Normalisation, Brussels.

EIA (1999). Systems Engineering Capability Model Interim Standard, EIA/IS/731.

GERAM (1997). Generalized Enterprise Reference Architecture and Methodology Version 1.5, IFAC-IFIP Task Force on Enterprise Integration, August.

IEC (1998). IEC 61499 Working Draft, Function Blocks for Industrial Process measurement and control systems, International Electrotechnical Commission, October.

ISO (2002). ISO/IEC 62264-1:2002 Final Draft standard, Enterprise-control system integration, Part 1: Models and Terminology, ISO/TC184/SC 5.

UEML (2003). Unified Enterprise Modeling Language (UEML) Thematic Network, IST-2001-34229, www.ueml.org.

UML (2003). UML 2.0 superstructure specification, ptc/03608-02, OMG, www.uml.org. 


\begin{tabular}{|c|c|c|c|}
\hline Requires $\$ & Situation & Competence & Knowledge \\
\hline Situation & & & \\
\hline Competence & & & \\
\hline Knowledge & & & \\
\hline
\end{tabular}

Table 1. : Working situation and its relationships

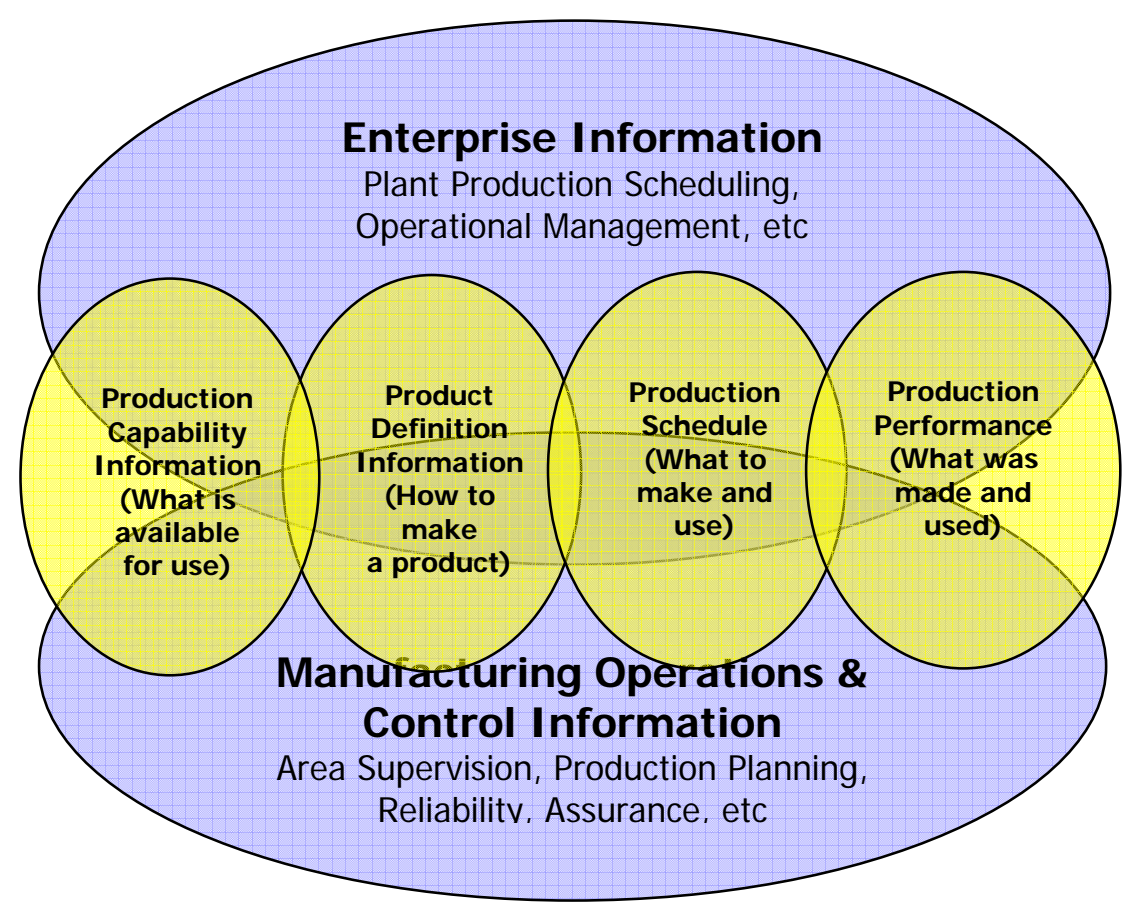

Fig. 1. Enterprise Control System integration framework (ISO, 2001)

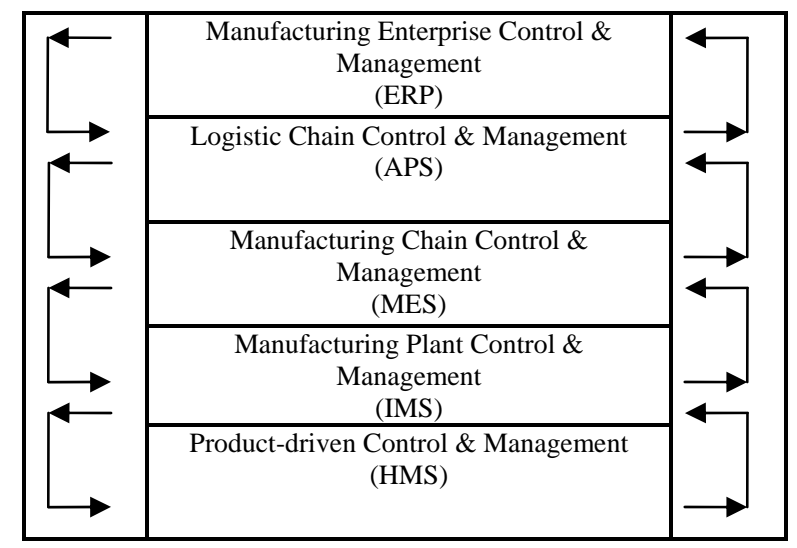

Fig. 2. Manufacturing Enterprise Control and Management Systems 
5. Intelligent

4. Interoperable

3. Integrated

2. Hierarchical

1. Isolated

Theoretical \& Modelling Paradigms

Kenetics \& MAS \& HMS

Cognitics \& Ontology \& Object-Oriented

Systemics \& Systems Engineering

Systems Theory \& Automatic Control

Empiricism \& Ad hoc approach

Fig. 3. Capability Profile between system architecture feature and the related theoretical and technical modelling framework

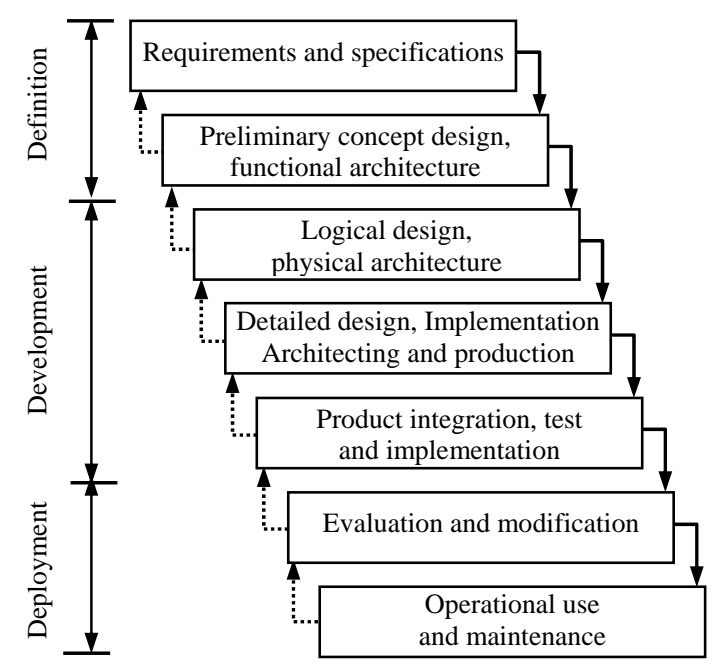

Fig. 4. Maturity model of the Information flows in a Systems Engineering life-cycle (EIA, 1999)

\begin{tabular}{|c|c|c|}
\hline Top-down & Aspect & Bottom-up \\
\hline Pre-determined & Strategy & Emergent \\
\hline Formal & Style & Informal \\
\hline Macro & Focus & Micro \\
\hline Centralized & Source & Distributed \\
\hline
\end{tabular}

Fig. 5. Comparison of the top-down vs. bottom-up approach to information ordering (Dias, et al., 2001)

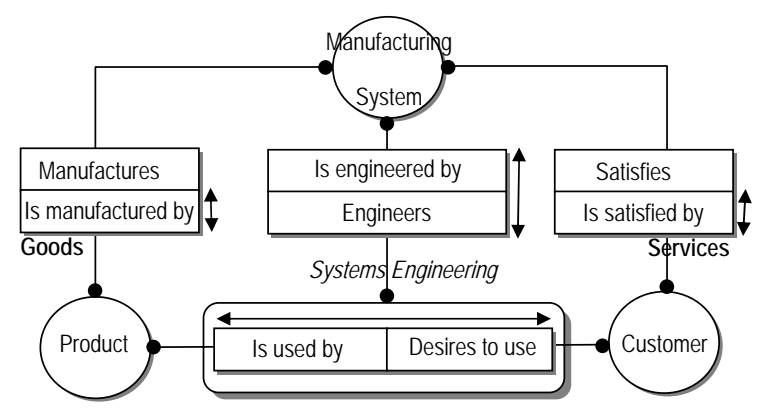

Fig. 6. N-dimension molecule representing a manufacturing system emerging from an atomic interaction (Lavigne, et al., in Monostori, et al., 2003). 


\begin{tabular}{|c|c|c|}
\hline Frameworks & Languages & Modules \\
\hline $\begin{array}{c}\text { CEN/ISO } 19439 \text { - Fram ework } \\
\text { for Modelling }\end{array}$ & $\begin{array}{c}\text { CEN/ISO } 19440- \\
\text { Constructs for Modelling }\end{array}$ & \multirow{2}{*}{$\begin{array}{c}\text { ENV } 13550 \\
\text { Model Execution Services } \\
\text { (EMEIS) }\end{array}$} \\
\hline \multirow{2}{*}{$\begin{array}{l}\text { ISO } 15745 \text { - Framework for } \\
\text { Application Integration }\end{array}$} & ISO 18629 - Process & \\
\hline & Specification Language & \multirow{2}{*}{$\begin{array}{l}\text { ISO IS } 15531 \\
\text { Mfg. Mgmt. } \\
\text { Data Exchange }\end{array}$} \\
\hline \multirow[t]{3}{*}{$\begin{array}{c}\text { ISO } 15288 \\
\text { Life Cycle Mgmt. }\end{array}$} & $\begin{array}{l}\text { ISO/IEC } 15414-O D P \\
\text { Enterprise Language }\end{array}$ & \\
\hline & $\begin{array}{c}\text { BPM I/BPML } \\
\text { Business Process } \\
\text { Modeling Language }\end{array}$ & $\begin{array}{l}\text { ISO DIS } 16100 \\
\text { Mfg. Software } \\
\text { Capability Profiling }\end{array}$ \\
\hline & $\begin{array}{c}\text { OMG/RfP } \\
\text { UML Profile for Business } \\
\text { Process Definition }\end{array}$ & $\begin{array}{l}\text { IEC/ISO } 62264 \\
\text { Control Systems } \\
\text { Integration }\end{array}$ \\
\hline
\end{tabular}

Fig. 7. : Standards related to Enterprise Engineering and Integration (UEML, 2003)

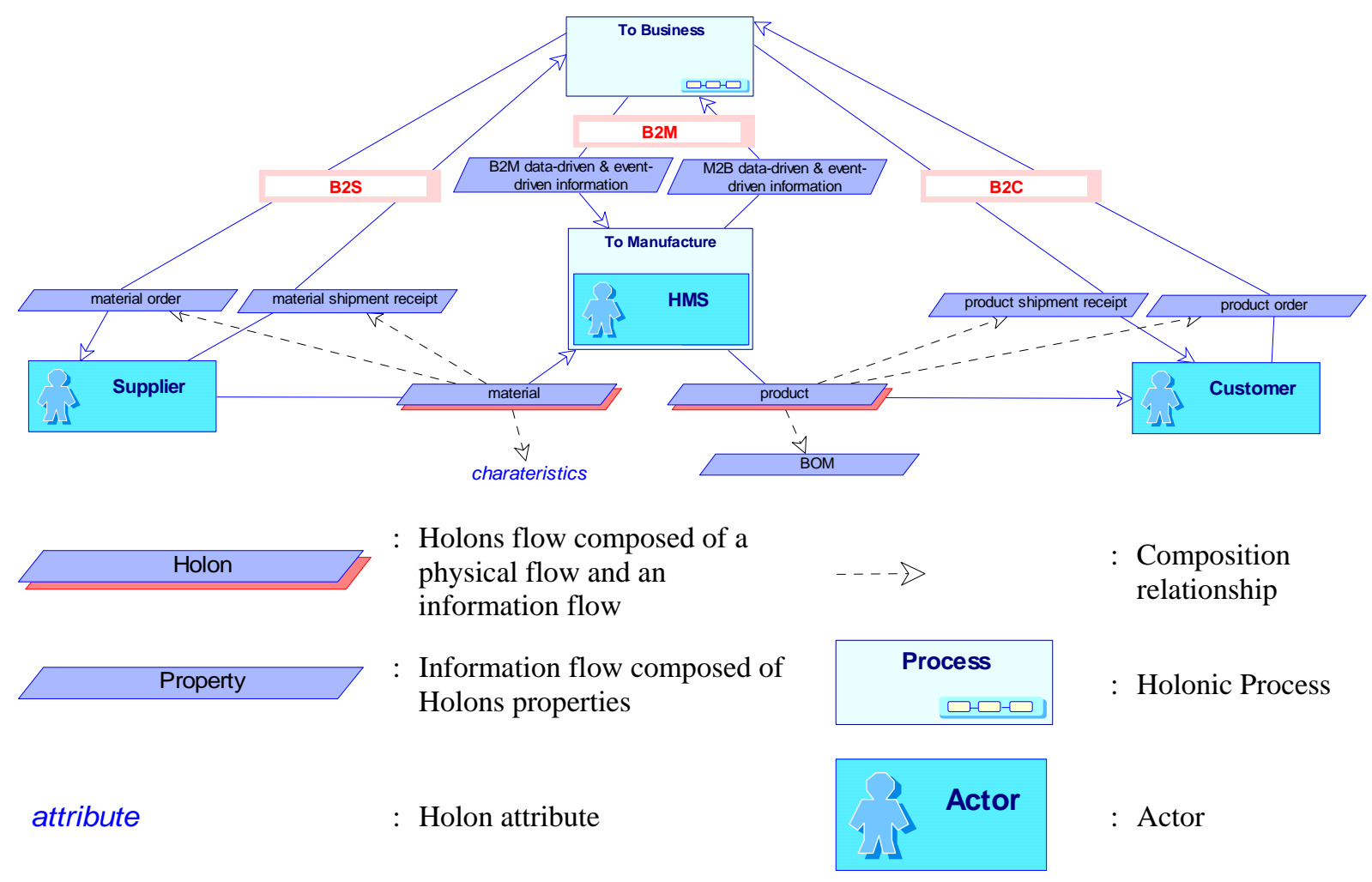

Fig. 8. Holonic Process Model of a B2M context 


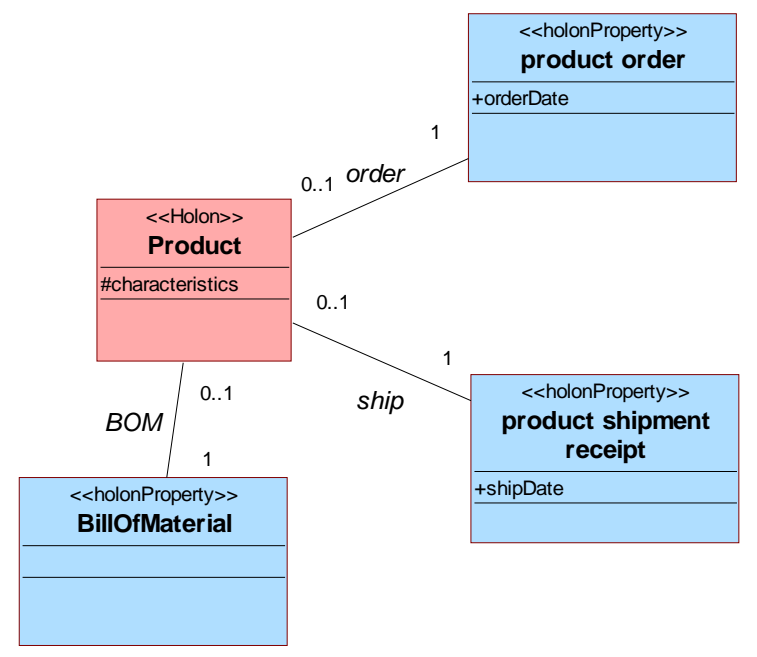

Fig. 9. Extract of the Holon class diagram for a B2M application

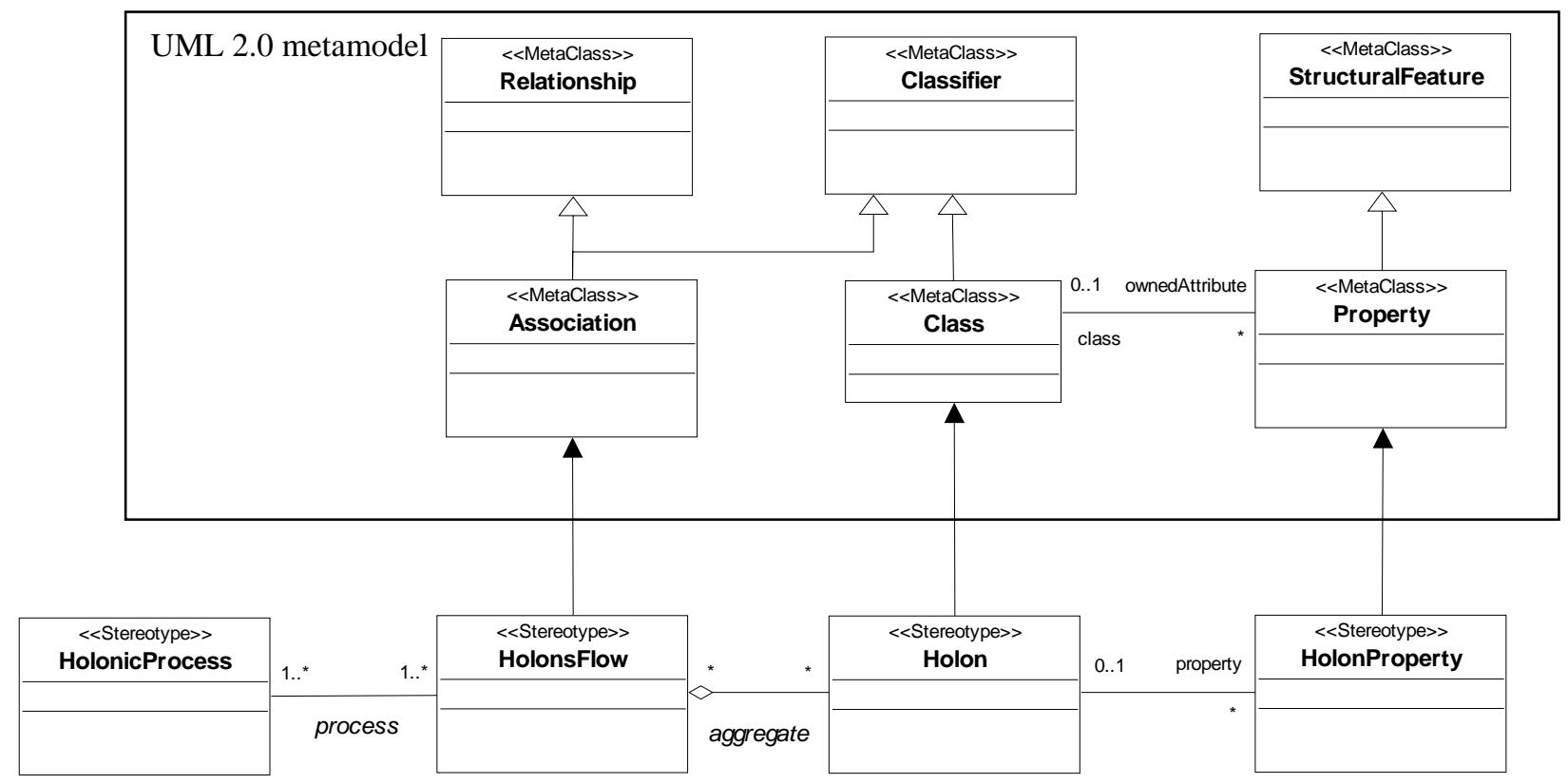

Fig. 10. Extract of the Metamodel for the Holonic Process Model 


\begin{tabular}{|c|c|c|c|c|}
\hline \multirow{2}{*}{\begin{tabular}{|l|r|} 
\\
System \\
models
\end{tabular}} & \multirow[b]{2}{*}{ Communication } & \multirow[b]{2}{*}{ Information } & \multicolumn{2}{|c|}{ Processing } \\
\hline & & & Data-driven & Event-driven \\
\hline \multirow{2}{*}{ Conceptual } & \multicolumn{4}{|c|}{ HMS - like } \\
\hline & \multicolumn{4}{|c|}{ Specialised UEML and UMML } \\
\hline Organisational & \multicolumn{4}{|c|}{ IEC/ISO 62264 based on UML notation } \\
\hline Operational & $\begin{array}{c}\text { IEC } \\
61499\end{array}$ & $\begin{array}{c}\text { Relational } \\
\text { Model }\end{array}$ & $\begin{array}{r}\text { IEC } 61499 \mathrm{~b} \\
\text { not }\end{array}$ & $\begin{array}{l}\text { ed on UML } \\
\text { ion }\end{array}$ \\
\hline Technical & \multicolumn{4}{|c|}{ MES Automation technology } \\
\hline
\end{tabular}

Fig. 11. HMESE framework 